Bull. Fac. Agric., Cairo Univ., 71: 331-340 (2020).

\title{
DETERMINATION OF GENETIC DIFFERENCES BETWEEN Artemisia monosperma PLANTS BY USING GENETIC FINGEPRINTING.
}

(Received: 30.12.2020)

\author{
By \\ A. N . M . El-Atla and *Warda Y. Ali \\ Environment and Arid Land Agriculture Division, Desert Research Center, \\ El-Matareya, Cairo, Egypt
}

\begin{abstract}
In the present study, three of the Egyptian Artemisia monosperma genotypes were selected from Bir al-Abd city in North Sinai, Egypt, for genetics analysis by using 5 of inter simple sequence repeat (ISSR) markers. The obtained results indicated that the ISSR primers were able to amplify DNA fragments showing, polymorphic DNA amplification patterns among the genotypes. The data indicated that out of the total 120 bands, 64 were polymorphic (64\%). The number of the observed bands ranged from two for the primer UBC849 to one in the primer UBC811with an average of 2.4 across for the tested genotypes. The data also showed the presence of reasonable number of alleles for every locus in the present study, which may be due of the nature to amplified ISSR loci that most to them are located to the expressed sequence tags (EST) in the transcribed regions of the genomic DNA sequences. UBC849 with average value to 7 . Consequently, most of the five ISSR loci in this study were useful for the evaluation of genetic diversity between the three Egyptian Artemisia monosperma genotypes. However, it is worth mentioning, this value expresses the existence to different alleles of one or more loci of homologous chromosomes. Polymorphism data content (PIC) value of the Artemisia monosperma genomic ISSR indicated temperate to high level of in formativeness with average PIC value to 0.42 over all the tested ISSR loci primers, where it ranged from 0.07 by using to UBC849 to 0.42 in UBC811 for all genotypes under research by a mean to 0.18 . Also, this study signalized a low heterozygosis level of the genotypes under research, so that for the variation between the number of alleles in each locus and number of effective alleles, so that to the existences to exclusive/specific alleles to the genotypes. The genetic analysis of the three Artemisia momosperma based on 5 ISSR markers detected 64 separate specific alleles, and also, that the three genotypes (G.1, G.2 and G.3) had alleles were unrivaled. So these five genotypes did not give conformable DNAfingerprints. It is noted that, largest number patented to the specific/unique alleles were of the genotype number 3 , where 30 specific alleles were patented to this genotype only.
\end{abstract}

Key words : FAA, Artemisia monosperma, ISSR, DNA, Fatty acids .

\section{INTRODUCTION}

The genus Artemisia L., Belongs to the Asteraceae family, compris in around 500 types of herbs growing mostly on beaches of North Africa and parts of Asia (Faten, et al.,2018). It has been classified into three sections: Absinthium DC, Artemisia L., Dracunculus Besser, Seriphidium Besser and Tridentatae $(R y b d$.). A general review of various systematic and evolutionary aspects of the genus, with a high light on cytogenetic and molecular database, and, although that of the current in frageneric classification does not of natural groups, and there is still without agreement about the global treatment of the genus despite the bitter taste of Artemisia a plant, some insects and rodents use it as an analgesic and food (Mohammed et al.,2018). The plant Artemisia is used in desert areas as a source of wood in setting fire for cooking, as an alternative to fossil fuels and also as a material to feed animals, and it is included in the pharmaceutical industries. These, in a real and serious way, given that the Artemisia monosperma plant is tolerant to drought and grows naturally in poor and extremely dry lands, and what has been discovered of its importance in the biofuel industry, requires a plan to convert it into a 
planted plant (Haouari and Ferchichi 2008). The sustainable conservation of the threatened plants requires evaluating the genetic diversity of different populations in different habitats to elucidate the genetic differences between related species and populations of each species Viruel et al.,2005). Sustainable conservation of natural plant species requires comprehensive knowledge of their morphological variation, karyological features and molecular genetic information that will be useful in selecting superior populations for conservation. Accordingly, the present study was conducted to achieve the following

\section{Objectives}

1-Molecular analysis using ISSR markers to help in the construction of the molecular genetic data based for Egyptian Artemisia monosperma.

2- Analysis of the DNA fingerprinting data for identification and discrimination of some Egyptian Artemisia monosperma genotypes using ISSR markers.

3- Measuring the concentration of fatty acids in Artemisia monosperma samples.

\section{MATERIALS AND METHODS}

The present study was carried out in the laboratory of Biotechnology Cairo University Research Park (CURP). The study aimed to examin the molecular characterization analysis for ISSR loci, and analysis of the DNA fingerprinting data, study of genetic diversity level and relationships among some Artemisia monosperma genotypes grown in North Sinai, Egypt, and measuring the concentration of fatty acids in Artemisia samples.

\section{A. Molecular analysis}

\section{A.1. Plant Materials}

Three genotypes were collected from individual plant selection program based on the vigorous growth parameters with some morphological differences. Three Egyptian genotypes of Artemisia monosperma were used and referred to in this study by G1 to G3. The young leaves were collected from three plants per genotype and subjected to molecular analysis.

\section{A.2. Methods}

\section{A.2.1. Extraction and purification of Genomic DNA}

The total DNA of the three genotypes was extracted from frozen leaf tissue, using the CTAB method, with slight modifications .

\section{A.2.2. PCR reaction mixture}

PCR amplification was carried out in $25 \mu \mathrm{l}$ reaction mixture composed of $2 \mu$ genomic DNA (30 ng/ $\mu \mathrm{l})$ as a template, 10 pmoles primer, $0.2 \mathrm{mM}$ of dNTP's mix (ABgene, Surrey, UK), 5X PCR buffer, $2 \mathrm{~m} \mathrm{M} \mathrm{MgCl} 2$, and 1 unit Taq DNA polymerase $(5 \mathrm{U} / 1 \mu \mathrm{l})$.

\section{PCR amplification}

These five ISSR primers were synthesized by metabion international AG, Martinsried /Deutschland. PCR amplification was performed in a thermos cycler (Eppendorf Master Cycler Gradient Eppendorf, Hamburg, Germany) programmed to fulfill 35 cycles after an initial denaturation cycle for $5 \mathrm{~min}$ at $94^{\circ} \mathrm{C}$. Each cycle consisted of a denaturation step at $94^{\circ} \mathrm{C}$ for $45 \mathrm{~s}$, an annealing step at $46^{\circ} \mathrm{C}-56^{\circ} \mathrm{C}$ for $50 \mathrm{~s}$, and an elongation step at $72^{\circ} \mathrm{C}$ for $60 \mathrm{~s}$. The primer extension segment was extended to $7 \mathrm{~min}$ at $72^{\circ} \mathrm{C}$ in the final cycle. Subsequently followed by10cycles of denaturation for $30 \mathrm{~s}$ at $94^{\circ} \mathrm{C}$, annealing for $45 \mathrm{~s}$ at $53^{\circ} \mathrm{C}$, extension for $45 \mathrm{~s}$ at $72^{\circ} \mathrm{C}$ followed by final extension for $12 \mathrm{~min}$ at $72^{\circ} \mathrm{C}$. Every reaction was repeated two times to guarantee the reproducibility of the results.

\section{Detection of ISSR products}

A DNA molecular weight marker (100 bp or $1 \mathrm{~kb}$ DNA ladder, Generuler) was used as DNA size markers. After the electrophoretic run, the gels were visualized under gel documentation model (Gel-Doc 2000 with Diversity Database software Ver. 2.1, Bio-Rad Laboratories, Hercules, California, USA) for gel analysis.

\section{Data analysis}

The genetic information was assessed for all ISSR loci using the following parameters; Observed number of alleles per locus (na), counts the number of alleles with zero allele (the alleles in case that no products were amplified in one or more genotypes), percent of polymorphic bands per ISSR locus, maximum number of bands per genotype, average of polymorphism, the number of unique (specific) alleles per genotype, and observed heterozygosity (Ho), as direct count and it was calculated by dividing the number of heterozygous samples per locus to the total number of samples or genotypes.

The effective number of alleles (NE) was calculated for each marker the formula: $\mathrm{NE}=$ $1 / \sum(\mathrm{E} / \mathrm{F}) 2$, where $\mathrm{E}$ refers to the total number of genotypes at each allele of locus $\mathrm{i}$, and $\mathrm{F}$ the total number of alleles of the locus $i$ in all genotypes. The heterozygosity index which also known as, polymorphism information contents (PIC) was calculated for each locus depends on number of alleles and the allele frequency from the formula: PIC $=1-\sum$ pi 2 where pi is the 
Table (1): A list of five ISSR markers, selected references and range of annealing temperature.

\begin{tabular}{|c|l|l|l|c|c|}
\hline $\begin{array}{c}\text { Loci } \\
\text { code }\end{array}$ & $\begin{array}{l}\text { ISSR } \\
\text { Loci }\end{array}$ & \multicolumn{1}{|c|}{ Sequence (5-3 ) } & \multicolumn{1}{|c|}{$\begin{array}{c}\text { Genbank Accessions } \\
\text { or References }\end{array}$} & $\begin{array}{c}\text { Ta } \\
\text { Repeat } \\
\text { motif }\end{array}$ \\
\hline UBC811 & EST & GAGAGAGAGAGA GAGAC & KY399971 & 51.78 & $(\mathrm{GA}) 8$ \\
\hline UBC818 & EST & CACACACACACA CAC AG & KC864751 & 51.78 & $(\mathrm{CA}) 8$ \\
\hline UPC 834 & EST & GAGAGAGAGAGAGAGAGAGAT & Mona S. W. and Najat A. B.,(2014) & 54.87 & $(\mathrm{GA}) 10$ \\
\hline UPC849 & EST & GAGAGAGAGAGAGAGAT & Mona S. W. and Najat A. B.,(2014) & 47.40 & $(\mathrm{GA}) 8$ \\
\hline UPC845 & EST & CTCTCTCTCTCTG & Rana T. S.,(2013) & 49 & $(\mathrm{CT}) 6$ \\
\hline
\end{tabular}

Ta refers to temperature of annealing

A master mix was prepared in a $2 \mathrm{ml}$ eppendorf tube according to the number of PCR reactions to be performed, with an extra reaction included to compensate the loss part of the solution due to frequent pipetting. An aliquot of $23 \mu 1$ master mix solution was dispensed in each PCR tube $(0.2 \mathrm{ml}$ eppendorf tube), containing $2 \mu 1$ of the appropriate template DNA

frequency of each allele. If PIC value calculated in this way, it is similar to the expression 'gene diversity'. Discriminating power for each locus (PD) was calculated as previous formula, but the allele frequency was replaced by the fragment or genotype frequency. Also, the heterozygosity level within each genotype was calculated. The genetic similarity coefficient (GS) between samples

Dice formula: GS $(i j)=2 a /(2 a+b+c)$

Where GS (ij) is the measure of the genetic similarity between individuals $i$ and $j$, (a) is the number of bands shared by $\mathrm{i}$ and $\mathrm{j}$, (b) is the number of bands present in (i) and (c) is the number of bands absent in $\mathrm{i}$ and present in $\mathrm{j}$.

\section{Statistical analysis}

All data were tabulated, calculated and statistically analyzed using the computer program SPSS software for windows version 22.0 (Statistical Package for Social Science, Armonk, NY: IBM Corp) Descriptive statistics was calculated in the form of Mean \pm Standard deviation (SD), (Table (1).

\section{RESULTS AND DISCUSSION}

Artemisia monosperma is a multipurpose plant and recognized as asource energy for people living in the desert. Also it is used in veterinary purposes and therapy of many human diseases as traditional medicine in African and Asian countries. Moreover, there is a shortage of the genetic research and studies on the spread of Artemisia monosperma in Egypt in terms genetic diversity which benefits in breeding genetic improvement and programs and of Artemisia monosperma.

\subsection{Molecular markers informative (Fig .1:5)}

The plant is monoecious and the flowers are generally unisexual with occasional hermaphrodite flowers, although, it has been shown that Artemisia monosperma can be geitonogamic (autogamy). It is worth mentioning that the Artemisia monosperma grading in Egypt and used in the present study belongs to Wild Artemisia monosperma. Currently, the only way to identify the high and low $\mathrm{PE}$ is the vegetative parts, by the vegetative parts analysis with high performance liquid chromatography (HPLC). Artemisia monosperma breeders are looking for a cheaper and quicker way to distinguish them such as through molecular markers, provided that the location of gene (s) controlling high PE content. In this study, three Egyptian Artemisia monosperma genotypes were used to analyse the molecular characterization and informative ISSR markers. Primers pairs were screened to reveal the polymorphisms in each of the three genotypes. But only Five ISSR primers were able of amplify bands and selected for our analysis of their numerous and polymorphic DNA amplification modality among the genotypes (Table 2) and (Fig. 2). The five ISSR loci considered, 8 of them produced only one or two bands per genotype and described as a single locus (Viruel et al., 2005). However, the other 5 loci (UBC811., UBC818., UPC 834., UPC849 and UPC845) produced more bands (two-three bands with some genotypes) than expected according to the diploid texture of this specie (if used ISSR markers). Analysis to the The plant is monoecious and the flowers are generally unisexual with occasional hermaphrodite flowers, although, it has been shown that Artemisia monosperma can be geitonogamic (autogamy). It is worth mentioning that the Artemisia monosperma grading in Egypt and used in the present study belongs to Wild Artemisia monosperma. Currently, the only way to identify the high and low PE is the vegetative parts, by the vegetative parts analysis with high performance liquid chromatography (HPLC). Artemisia monosperma breeders are looking for a cheaper 
and quicker way to distinguish them such as through molecular markers, provided that the location of gene (s) controlling high PE content. In this study, three Egyptian Artemisia monosperma genotypes were used to analyses the molecular characterization and informative ISSR markers. Primers pairs were screened to reveal the polymorphisms in each of the three genotypes. But only Five ISSR primers were able of amplify bands and selected for our analysis of their numerous and polymorphic DNA amplification modality among the genotypes (Table 2) and (Fig. 2). The five ISSR loci considered, 8 of them produced only one or two bands per genotype and described as a single locus (Viruel et al., 2005). However, the other 5 loci (UBC811., UBC818., UPC 834., UPC849 and UPC845) produced more bands (two-three bands with some genotypes) than expected according to the diploid texture of this specie (if used ISSR markers). Analysis to the five ISSR loci of genotypes exposed a total of 120 bands or alleles and not across genotypes with 0 alleles. This with repeating the interaction more than once (Table 2). Out to 120 bands, 15 bands were polymorphic with a rather high level to polymorphism (63.3\%) among the genotypes to ISSR (Table 2). These results are consistent with the findings of Abdelfattah et al., (2012), who studied morphological diversity and molecular polymorphism as revealed by random amplified polymorphic DNA of three populations of Artemisia, and reported 2 populations differ to chromosome length, being $4.85 \pm 0.42 \mu \mathrm{m}$ to those growing in wadi beds and $3.81 \pm 0.28 \mu \mathrm{m}$ for the population growing on the terraces. participating in, asource to genetic variation between the different genetic sites with Artemisia monosperma strains. The two loci in this search produced a few number to alleles and Tanya et al. (2013). In the same context. Vischi M., et al. (2017) reported very limited number of alleles ranged from 2 to 3 alleles per locus using 120 ISSR loci, Whereas, the estimated number to ISSR alleles depends on the number to samples and the genetic variability of the samples in addition to the number of ISSRs primers used and their genome coverage. Also, the difference in the number to amplified alleles in any ISSR locus is a result of the veration of rates for mutation to that locus .This moderate percentage to polymorphism may also have been influenced by the number to repeated nucleotides, whereas the ISSR markers in case to few number of repeated nucleotides ( 2 to $3 \mathrm{bp}$ ) are less polymorphic than of the case of a high number to repeated nucleotides as reported by Gadaleta et al. (2007). Because most ISSR loci in the present search consist of repeated dinucleotide, hence the percentages to polymorphism between the studied genotypes were between medium slightly above with the two ISSR loci.

Data in Table (3) that among seven natural local populations of the aromatic shrubby herb Artemisia judaica L. from different sites in South Sinai, Egypt ,by 10 selected RAPD primers, the results that there is an average of 8.7 amplified bands per primer and $57.47 \%$ polymorphism, indicating a marked genetic variation in the examined populations.

Table(2):Various parameters and molecular characterization of the PCR products for three microsatellite markers (ISSR) in Three Egyptian Artemisia monosperma genotypes:

\begin{tabular}{|c|c|c|c|c|c|c|c|c|}
\hline No & ISSR loci code & $\begin{array}{c}\text { Total } \\
\text { alleles(Na) }\end{array}$ & Polymorphic & $\begin{array}{c}\text { Maximum number } \\
\text { of alleles/Genotype }\end{array}$ & NE $^{\mathbf{a}}$ & HO $^{\mathbf{b}}$ & PIC $^{\mathbf{c}}$ & DP $^{\mathbf{d}}$ \\
\hline $\mathbf{1}$ & UBC811 & 12 & 6 & 2 & 6 & 1.2 & 0.15 & 0.94 \\
\hline $\mathbf{2}$ & UBC818 & 26 & 14 & 6.5 & 14 & 2.8 & 0.33 & 0.40 \\
\hline $\mathbf{3}$ & UPC 834 & 23 & 15 & 1.5 & 15 & 3 & 0.30 & 0.85 \\
\hline $\mathbf{4}$ & UPC849 & 35 & 15 & 2.3 & 15 & 3 & 0.42 & 0.85 \\
\hline $\mathbf{5}$ & UPC845 & 23 & 14 & 1.6 & 14 & 2.8 & 0.30 & 0.86 \\
\hline & Total & 120 & 64 & & & & & \\
\hline & \%polymorphism & 0.64 & & & & & & \\
\hline & Mean & $\mathbf{2 3 . 8}$ & $\mathbf{1 2 . 8}$ & $\mathbf{2 . 7}$ & $\mathbf{1 2 . 8}$ & $\mathbf{2 . 5 6}$ & $\mathbf{4 . 7 2}$ & $\mathbf{3 . 8 6}$ \\
\hline
\end{tabular}

${ }^{a}$ Effective number of alleles

${ }^{\mathbf{b}}$ Direct count heterozygosity or observed heterozygosity is calculated according to Nei (1973), 0.00 indicates that the locus is homozygous over all the studied genotypes.

${ }^{\mathfrak{c}}$ The polymorphism information content or expected heterozygosity, reflect the ability of a marker for detecting polymorphism between the genotypes, depending on the numbers of detectable alleles and their frequency.

${ }^{\mathbf{d}}$ The probability of discriminating between two genotypes or more with every locus. It is calculated as 1-P $(\mathrm{P}=$ probability of matching fingerprints). 


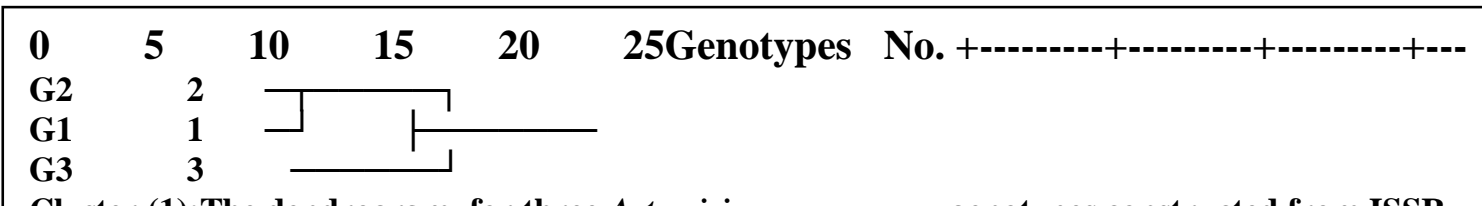

Cluster (1):The dendrogram for three Artemisia monosperma genotypes constructed from ISSR
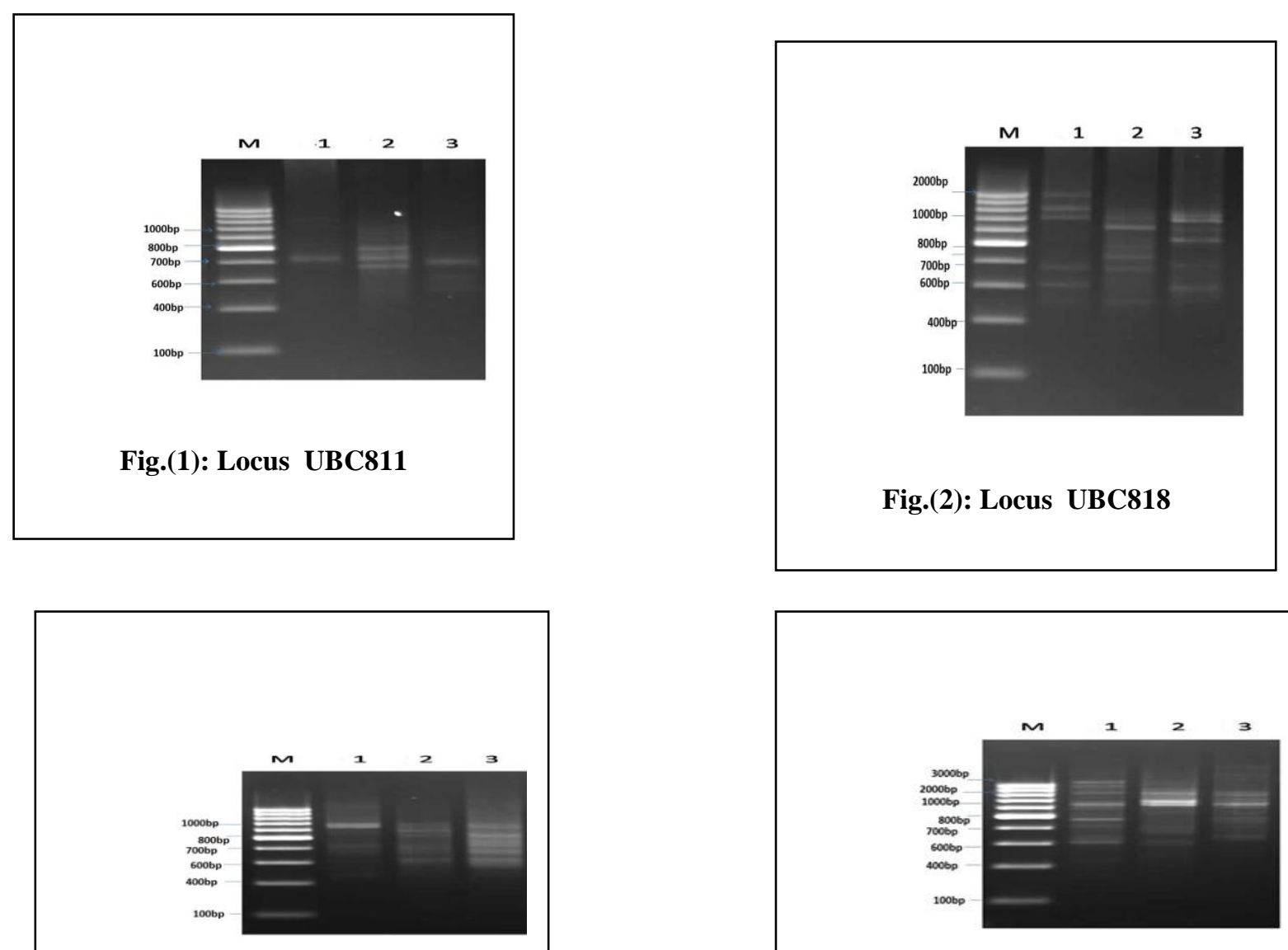

Fig.(3): Locus UBC834
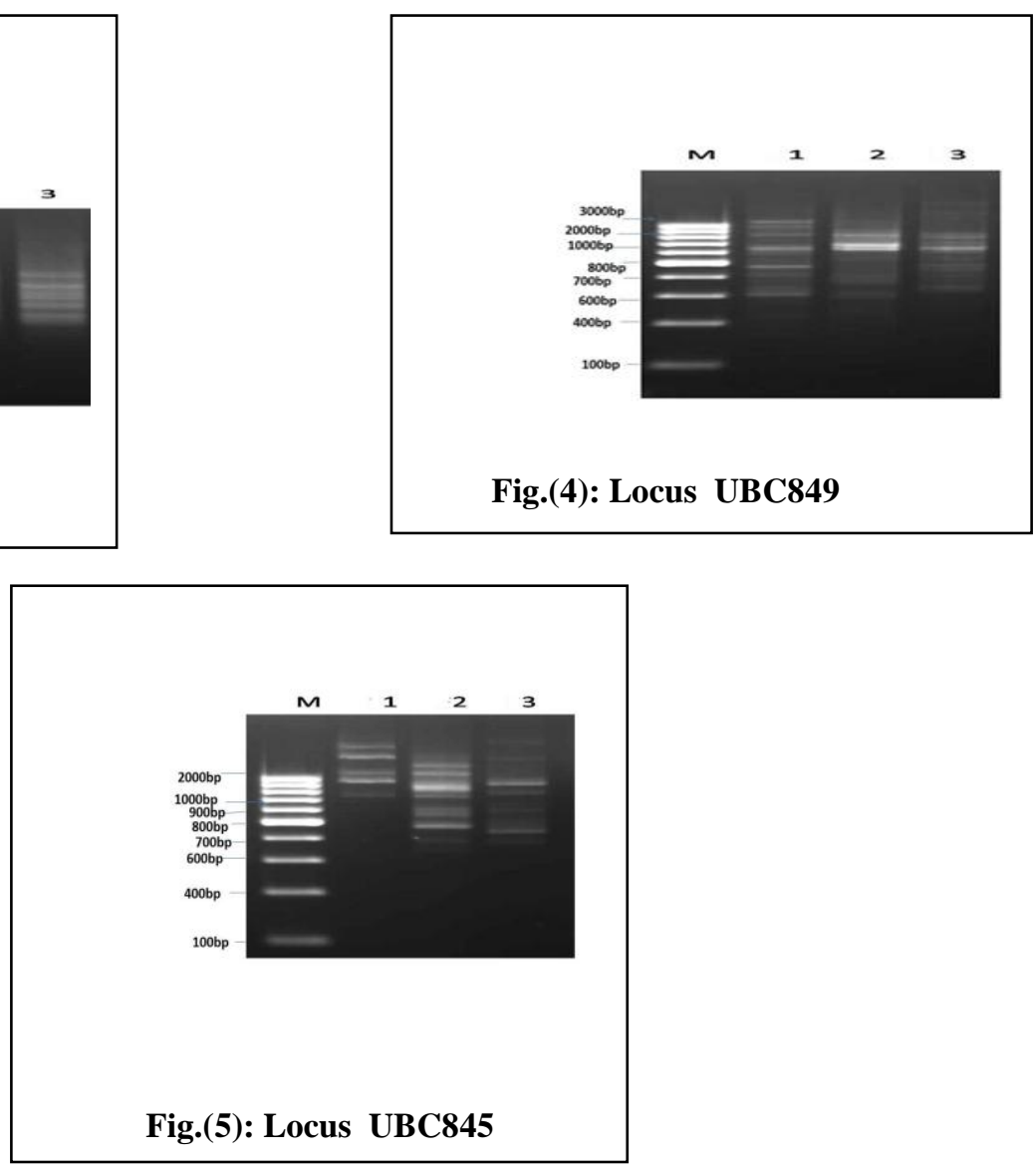
Table (3): number of different genotypes in each genotype.

\begin{tabular}{|l|l|l|l|l|c|}
\hline Locus & $\begin{array}{c}\text { Polymorphic } \\
\text { band }\end{array}$ & $\begin{array}{c}\text { Total no. } \\
\text { bands }\end{array}$ & $\begin{array}{c}\text { \%Polymor } \\
\text { physim }\end{array}$ & $\begin{array}{c}\text { Average } \\
\text { heterozgostity }\end{array}$ & $\begin{array}{c}\text { Size range } \\
\text { (bp) }\end{array}$ \\
\hline UBC811 & 6 & 12 & $50 \%$ & $\mathbf{0 . 4 2}$ & $100-700$ \\
\hline UBC818 & 16 & $\mathbf{3 0}$ & $\mathbf{5 3 \%}$ & $\mathbf{0 . 1 6}$ & $100-1000$ \\
\hline UBC834 & 14 & 23 & $70 \%$ & 0.14 & $100-700$ \\
\hline UBC849 & 19 & $\mathbf{3 0}$ & $\mathbf{6 3 \%}$ & $\mathbf{0 . 0 7}$ & $100-1000$ \\
\hline UBC845 & $\mathbf{2 0}$ & $\mathbf{2 5}$ & $\mathbf{8 0 \%}$ & $\mathbf{0 . 1 3}$ & $\mathbf{1 0 0 - 1 0 0 0}$ \\
\hline
\end{tabular}

It is worth mentioning, that most of the ISSR lociin the present study produced amplicon size within the expected range. The present are in results harmony with similar analysis by Contrary, reported by Bodian et al. (2012). Especially these genotypes have originated in a limited geographical area. Additionally, nature of the self-pollination in Artemisia monosperma has the greatest impact. Polymorphism Information Content (PIC) or gene diversity, which express of the appreciation of the discriminatory power of each ISSR locus. It is calculated depending on both the number of alleles per locus and their frequency distribution within the genotypes. This was used to evaluate their inform ativeness level and accordingly defined into high (PIC > 0.5), moderate $(0.5$ $>$ PIC >0.25), and low (PIC < 0.25 ) categories. This result was comparable to those obtained by Tanya et al. (2011), Most ISSR loci in this study showed PIC values more than 0.25 ; hence, it can be described as moderately informative to study genetic diversity.Two EST-SSR markers, i.e., UBC811., UBC818., UPC 834., UPC849 and UPC845 were most importantly showing a high degree of PIC (more than $50 \%$.).

While Khaled and Abdelrezak, (2019) examined the genetic variability to 18 individuals of Artemisia herba-alba from 3 diverse elevations of Green Mountain to Libya by using sequence related amplified polymorphism (SRAP) and random amplified polymorphic DNA method, so that the results showed distinctive SRAP and RAPD banding pattern in this species scoring a total of 17 SRAP and 61 RAPD bands including $94.12 \%$ and 100 $\%$ polymorphic with amplicon size ranging from 50 to $1600 \mathrm{bp}$ and 150 to $1800 \mathrm{bp}$, respectively, and also that the Phylogenetic relationship between the genotypes was able to divide the samples into two main groups with genetic similarity value ranged from 41 to $84 \%$. The data obtained in such studies are very important information that may help estimate and distribute the genetic structure contribution in conservation strategies (Ohsawa and Ide 2008). In our results the research examined a lot of genetic elevations to Artemisia plants under test, and its education with to Abdelfattah et al.,(2012) the analysis of morphological variation and molecular polymorphism as revealed by random amplified polymorphic DNA (RAPD) of ten populations of Artemisia monosperma and Artemisia judaica confirmed the differentiation of A. monosperma and $A$. judaica as two distinct species and showed wider variations among $A$. judaica populations compared to those of A. monosperma populations. Karyotype analysis revealed that all A. monosperma populations are tetraploid with $2 \mathrm{n}=36$ and a basic number of $\mathrm{x}=9$, while all samples of $A$. judaica are diploid with $2 \mathrm{n}=16$ and $\mathrm{x}=8$. Like most other species of Artemisia both species have symmetric karyotype but the chromosomes of A. monosperma are generally shorter and three populations of this species have a B. chromosome, and also that to in Tunisia was addressed by Haouari and Ferchichi,(2008) using ISSR markers; the results indicated patchy distribution to the genetic variability among different populations to this species revealing a contribution of local ecological and geographic conditions on its variability, and Faten et al.,(2018) investigation of genetic diversity with RAPD and ISSR markers to Artemisia herba, showed that a high level of genetic diversity within populations revealed either with RAPD and ISSR markers $\left(\mathrm{Na}^{1} / 4\right.$ 1.67, PPL $1 / 466.5 \%, \mathrm{H}$ $1 / 4$ 0.26, I $1 / 40.38$ and $\mathrm{Na}^{1 / 1} / 4$ 1.7, PPL $1 / 469.8 \%, \mathrm{H}$ $1 / 40.26$, I $1 / 40.38$, respectively). The level of genetic diversity varied across populations and chemo types. Populations from the athujone/trans-sabinyl acetate chemotype exhibited the highest genetic diversity as revealed by the RAPD markers. However, populations from a-thujone/camphor/b-thujone chemotype showed the important genetic variation determined by ISSR markers. 
Table (4):Degree of polymorphism and information content for 5 ISSR primers along with their sequences applied to 3 Artemisia genotype:

\begin{tabular}{|c|c|l|c|c|c|c|}
\hline $\mathbf{N}$ & Primer. & Sequence (5-3) Forward & \multicolumn{3}{|c|}{} & $\begin{array}{c}\text { \% } \\
\text { N }\end{array}$ \\
\cline { 4 - 6 } & & $\begin{array}{c}\text { Total } \\
(\mathbf{T})\end{array}$ & $\begin{array}{c}\text { Polymorphi } \\
(\mathbf{p o l})\end{array}$ & $\begin{array}{c}\text { Length } \\
\text { range (bp) }\end{array}$ & $\begin{array}{c}\text { polymorphism } \\
\text { (pol/TX100) }\end{array}$ \\
\hline 1 & UBC811 & GAGAGAGAGAGA GAGAC & $\mathbf{1 2}$ & $\mathbf{7}$ & $\mathbf{1 0 0 - 7 0 0}$ & $\mathbf{5 0 \%}$ \\
\hline 2 & UBC818 & CACACACACACA CAC AG & $\mathbf{3 0}$ & $\mathbf{1 5}$ & $\mathbf{1 0 0 - 1 0 0 0}$ & $\mathbf{5 3 \%}$ \\
\hline 3 & UBC834 & GAGAGAGAGAGAGAGAGAGAT & $\mathbf{2 3}$ & $\mathbf{2 1}$ & $\mathbf{1 0 0 - 7 0 0}$ & $\mathbf{7 0 \%}$ \\
\hline 4 & UBC849 & GAGAGAGAGAGAGAGAT & $\mathbf{3 0}$ & $\mathbf{2 4}$ & $\mathbf{1 0 0 - 1 0 0 0}$ & $\mathbf{6 3 \%}$ \\
\hline 5 & UBC845 & CTCTCTCTCTCTG & $\mathbf{2 5}$ & $\mathbf{8}$ & $\mathbf{1 0 0 - 1 0 0 0}$ & $\mathbf{8 0 \%}$ \\
\hline
\end{tabular}

PIC, Average polymorphic information content for polymorphic bands.

It is worth mentioning that the level to genetic activity could also be due to high mutational rate at ISSR loci which are influenced, used to the structure, length to the repeated units, and also that to the loci with large number to repeated units (ISSR unites) tend to show high mutational rate. Perhaps, most ISSR loci used to my study consisting to hgih number to repeated units. As a result, any one to the alleles have any mutations may create a heterozygous .

A significant genetic differentiation among populations and among chemotypes was detected.

Especially, Table (4), that genotypes have originated in a relatively small geographical region. So the average to heterozygosity degree across the 5 amplified ISSR loci in this study was fairly low. Moreover, Egyptian Artemisia plants have a narrow genetic base leading of low variability with in the genotypes. These results were comparable to those obtained by Zakkia Gul et al., (2019) where the genetic diversity between Artemisia species by estimated using genetic distances (GD) out of genomic, proteomic and morphological documentation and that to Total crude protein concentration in leaves to Artemisia gemilini $(19.4 \% \pm 0.46$, range 18.5-20.7\%) and Artemisia bravifolia (19.3 $\% \pm 0.53$, range 17.6-20.7 \%). SDS-PAGE revealed specific protein bands only in $A$. gemilini. Total genomic DNA extracted from bark using optimized isolation protocol., adipdcution our results are with Mona and Najat,(2014). They studied genetic diversity between populations and a dendrogram constructed to in agreement by inter-simple sequence repeat (UBC810, UBC811,UBC818, UBC834 and UBC849), the results gave the best amplification which produced a total of 43 polymorphic bands and the number of polymorphic loci was 20 and the percentage of polymorphism was $90.47 \%$, so the similarity result indicates the presence of high level genetic diversity between populations and a dendrogram constructed by UPGMA method, and also to Mohammad et al,(2018) investigation Studies on the genetic variation in marginal populations and differentiation between them are essential for assessment of best gene conservation strategies and sampling schemes to Salvadora persica, by used to ISSR markers, so that to The levels of genetic diversity maintained within populations of $S$. persica indicate that an appropriate sampling design for ex situ safeguarding should capture the majority of genetic diversity found within these taxa to help ensure the long term viability of this species. Furthermore, it could be inferred that ISSR markers are suitable tools for the evaluation of genetic diversity and relationships with in the Salvadora persica.(Table 5).

Table (5):survey of SSRs ramplicons across Five plants of Artomisia monpsperma using SSRsr primer.

\begin{tabular}{|c|c|c|c|c|}
\hline $\begin{array}{l}\text { DNA } \\
\text { Marker }\end{array}$ & Size (bp) & \multicolumn{3}{|c|}{$\begin{array}{c}\text { Compostate gene } \\
\text { type }\end{array}$} \\
\hline UBC811 & $\mathbf{1 0 0 - 7 0 0}$ & $\mathbf{1}$ & $\mathbf{2}$ & $\mathbf{3}$ \\
\hline UBC818 & $\mathbf{1 0 0 - 1 0 0 0}$ & 1 & 1 & 1 \\
\hline UBC834 & $\mathbf{1 0 0 - 7 0 0}$ & 1 & 1 & 1 \\
\hline UBC849 & $\mathbf{1 0 0 - 1 0 0 0}$ & 1 & 1 & 1 \\
\hline UBC845 & $\mathbf{1 0 0 - 1 0 0 0}$ & 1 & 1 & 1 \\
\hline Total & $\mathbf{5}$ & 5 & 5 & 5 \\
\hline
\end{tabular}

where (1) means presence (0) means absence and shading means specific marker .

\subsection{Genetic fingerprints for discrimination and conservation to the Egyptian Artemisia monosperma genotypes}

The average to matching fingerprints between the three Egyptian Artemisia monosperma genotypes of the level of all loci, confirms the intermediate degree to similarity between them. A possible explanation is that these genotypes derived from seeds reproduction. Taking into account,existence of a small proportion to outcross pollination. Whereas, genetic segregation is more effective in the emergence to species diversity than domestication . 
The genetic analysis to the 3 Artemisia sp genotypes based on 5 ISSR markers detected 3distinct specific alleles.

Three genotypes (G.1, G.2 and G.3) had alleles were unique. Wherever, five specific alleles considered as positive specific/unique alleles ${ }^{(+)}$, (Table 5). So these five genotypes did not give identical DNA-fingerprints. The nonunique polymorphic band research resulted for the five amplified loci. And these bands that to provide further ability of distinguish between the studied Artemisia plant genotypes, through presence or absence to these bands. Consequently, none of the pairs to Artemisia genotypes in the present research considered as identical genotypes. On the other side, sign up 12 unique alleles to in the time study can be accompanied with a number to novel functional alleles. This can be used of the improvement to Egyptian Artemisia.

So, modern molecular techniques could provide more information for discovering the genetic diversity among Egyptian Artemisia as bioenergy crop,aromatiac and medicinal plant at the level of DNA. Also, the combination between morphology and molecular description can give trend for conservation and breeding purposes.

3.3. The amplified alleles from ISSR loci and association with genes responsiblefor oleic acid content, (Table 6).

$\begin{array}{cccc}\text { Genotypes } & \text { G1 } & \text { G2 } & \text { G3 } \\ \text { G1 } & \mathbf{1 . 0 0} & & \\ \text { G2 } & \mathbf{0 . 5 0} & \mathbf{1 . 0 0} & \\ \text { G3 } & \mathbf{0 . 6 5} & \mathbf{0 . 6 7} & \mathbf{1 . 0 0}\end{array}$

As the pedigree data of the analyzed genotypesin the present study are not available. Because, mating system in Artemisia is normally self-pollination with avery limited proportion of out cross pollination. While, on the other hand the lowest similarity degree was 0.67 between genotypes number 2 and 3 , also was low comparatively between genotype number 2 and most rest of the genotypes(Table7).This means that these genotypes have the highest genetic distance and thus differ genetically from each other. There may be some reasons to explain this reduction. It is likely that the genetic diversity developed even among clonal offspring of the same cultivar and this is the result of accumulation of somatic mutations over many years. it can't disregard role of the genetic segregation after limited proportion of the out cross-pollination in the main source of these genotypes. All of that would have caused release of several lines genetically different which might have originated from the same source. In the present study, the genotypes under study were clustered and the dendrogram could be divided into four sections or clusters.Cluster 1 consisted of four genotypes (G.1, G.2,and G.3). Genotypes 7 and 10 showed the highest genetic similarity

Table (6): Heterozygosity grade and specific/Unique alleles within genotypes under study

\begin{tabular}{|c|c|c|c|}
\hline No & Genotypes & Heterozygosity & Specific/Unique alleles ${ }^{(+o r-)}$ \\
\hline 1 & G1 & 0.8 & 0.34 \\
G2 & & $\begin{array}{r}\text { UBC811_400bp(-),UBC 818_700 bp(+) } \\
\text { UBC834_1000 bp(+),UBC849_1000bp(+) } \\
\text { UBC845_2000bp+ }\end{array}$ \\
\hline 3 & G3 & 0.64 & \\
\hline & Mean & 0.34 & \\
\hline
\end{tabular}

${ }^{(+)}$indicates that the unique alleles are positive or present but ${ }^{(-)}$negative unique alleles.

\subsection{Genetic similarity and clustering of the genotypes}

Among the several co-dominant markers, the ISSRs have several advantages due to their codominant nature, are abundant in the genome, are highly reproducible, possess hyperpolymorphism, are rapidly evolving, and can be applied both on an infraspecific level and between related species. Table (7): Similarity indices $(\%)$ calculated by Dice computer package amongten Artemisia monosperma genotypes using five ISSR primers : and formed a separate sub cluster. Also, G.1 and G. 5were very closely related to each other.

Data based on Average Linkage (Between Groups), using Similarity computed according to Dice coefficient, with 40 fragments. Whereas, Cluster consisted also of three genotypes (genotypes 1, 2and 3); it was observed that three genotypes were very closely related to each other, especially genotype 1 with 2 (0.63). Where, both genotypes showed high genetic distance with the rest of Artemisia genotypes. Especially genotype 3 showed highest genetic 
distance with the rest genotypes under study. In fact, the dendrogram generally indicates the genetic relationships among set of genotypes in a population and may express the evolutionary and parentage history for thus genotypes. This is in a case that the samples of population under study were numerous and diverse enough as reported by Tran M.H., et al(2004). Consequently, the dendrogram in the present study was just to assessment structure of the genetic variation not to understand any evolutionary relationships. In conclusion, we can conclude out of results this part of the present study. In the three ISSR markers detected mode rate number of the alleles per locus and high percentage of polymorphism. The average of heterozygosity degree in the genotypes and across the 5 amplified ISSR loci in this study was fairly low. It has been pointed out that one of the reasons for this, the nature of amplified ISSR loci that most of them are locatedin transcribed regions or expressed sequence tags (ISSR)not genomic DNA sequences.Consequently, the performance of agiven ISSR markers to measure the polymorphism. In this context, some alleles or bands were identified in the genotypes under study and matched to those identified in previous studies, for example alleles associated with toxicity.

\section{REFERENCES}

Abdelfattah B., Wafaa M., Sahar A., Sahar S. and Amal S.,(2012). Genetic diversity in Artemisia monosperma and Artemisia judaica populations in Egypt based on morphological, karyological and molecular variations., Journal of Medicinal Plants Research Vol. 6(1), pp. 66-78, 9.

Bodian A., Mohamed A. and Khadidiatou N. (2012). Genetic diversity analysis of date palm (Phoenix datylifera L.) cultivars from Figuig oasis (Morocco) using SSR markers. International Journal of Science and Advanced Technology. 2 (3):96-104.

Faten Y., Najoua R ., Sameh M ., Mohamed

B. and Chokri M., (2018). Relationship between chemotypic and genetic diversity of naturalpopulations of Artemisia herbaalba Asso growing wild in Tunisia., Phytochemistry 148: 48-56.

Gadaleta A., Mangini G., Mulè G. and Blanco A. (2007).Characterization of dinucleotide and trinucleotide EST-derived microsatellites in the wheat genome., Euphytica J., 153:73-85.

Haouari M.and Ferchichi A.,( 2008 ). Study of genetic polymorphism of Artemisia herbaalba from Tunisia using ISSR markers.,African Journal of Biotechnology Vol. 7 (1), pp. 044-050.

Khaled E. and Abdelrezak E.,(2019). Genetic Diversity of Artemisia herba-alba in Libyan Green Mountain., Iranian Journal of Science and Technology, Transactions A: Science, 43:1507-1512.

Mohammad A. M.,Davood S., Gholam R. S.S. and Fatemeh S., (2018). Assessment of genetic diversity in Salvadora persica L. based on inter simple sequence repeat (ISSR) genetic marker., Journal of Genetic Engineering and Biotechnology.,(16): 661-667.

Mona S. W and Najat A. B.,(2014). Inter-simple sequence repeat (ISSR) analysis to molecular characteristic determination of Heliotropium digynum in Saudi Arabia., International Journal of Advanced Research, Volume 2, Issue (10): 902-906.

Ohsawa T. and Ide Y ( 2008 ). Global patterns of genetic variation in plant species along vertical and horizontal gradients on mountains. Glob Ecol Biogeogr 17:152163.

Tanya P, Taeprayoon P, Hadkam Y, Srinives P (2011) Genetic diversity among Jatropha and Jatropha-related species based on ISSR markers. Plant Mol Biol Rep 29(1):252-264

Tran M.H., Nguyen T. P. T., Nguyen T. T., Tran H.T., ( 2004 ) . Artemisia vulgaris L. from Vietnam: Chemical Variability and Composition of the Oil Along the Vegetative Life of the Plant., Journal of Essential Oil Research V16(4):358-361.

Vischi M.,Cristina ., Steluta R., Luca P.and Rachele M.,( 2017 ) . Genetic Diversity of Walnut (Juglans Regia L.) the in Eastern Italian Alps.,Forest Articial .,V8,P81.

Paolo Ermacora 1, Guido Cipriani 1, Donatella Paffetti 3,4, Cristina Vettori 4 and Raffaele Testolin 1 Viruel M. A., Escribano P., Barbieri M., Ferri M. and Hormaza J. I. (2005). Fingerprinting, embryo type and geographic differentiation in mango (Mangifera indica L., Anacardiaceae) with microsatellites. Molecular breeding. 14: 383-383. 
Viruel M.A., Escribano P., Barbieri M., Ferri M. and Hormaza, J.I. (2005). Fingerprinting, embryo type and geographic differentiation in mango (Mangifera indica L., Anacardiaceae) with microsatellites. Mol. Breed. 15: 383-393.
Zakkia G., Imtiaz A. K., Chandni K.and Tika K.,(2019). Comparative genomic, proteomic and morphological studies in two indigenous artemisia species collected from high mountains of Karakorum and himalaya in Gilgit Baltistan., Plants \& Agriculture Research, V(9),Issue 1.

$$
\begin{aligned}
& \text { Artemisia monosperma تحديد الإختلافات الجينية بين نباتات الأرطماسيا مونوسبيرما } \\
& \text { بإستخدام البصمة الوراثية } \\
& \text { أحمد نثأت محمد العطلة - وردة يوسف على } \\
& \text { شعبة البيئة وزراعات المناطق الجافة ـ مركز بحوث الصحراء ـ الدطرية ـ القاهرة - مصر }
\end{aligned}
$$

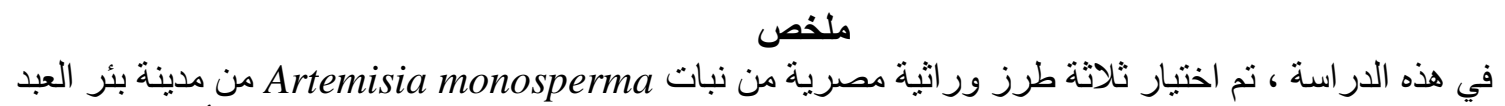

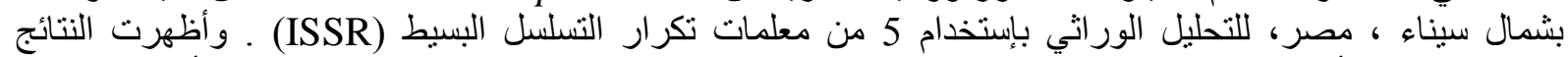

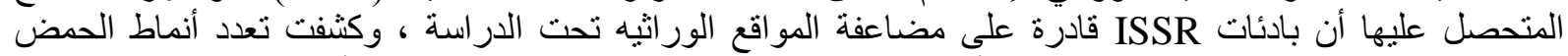

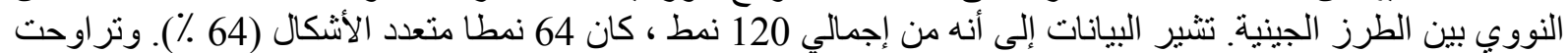

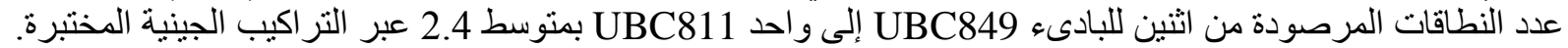

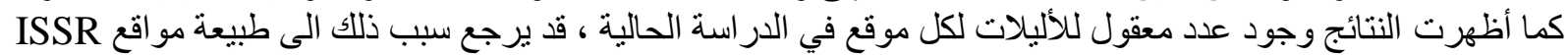

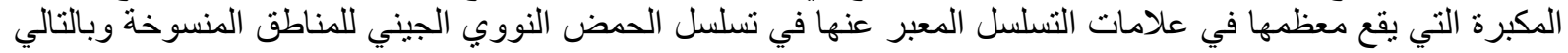

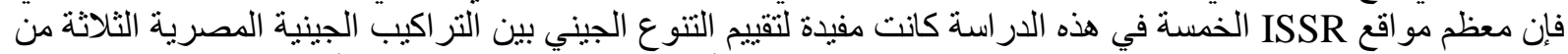

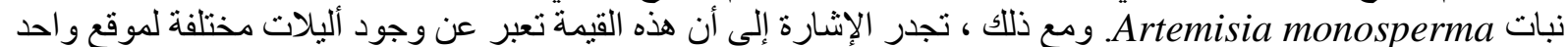

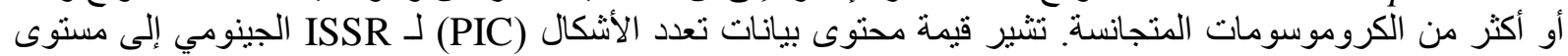

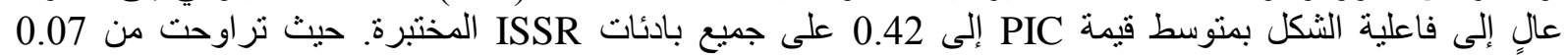

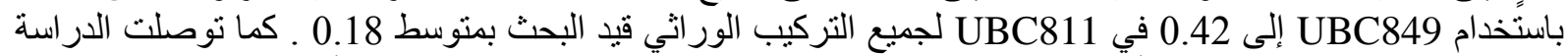

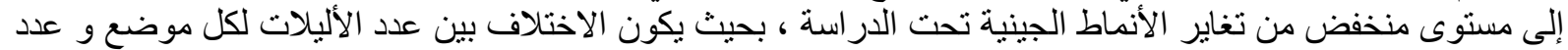

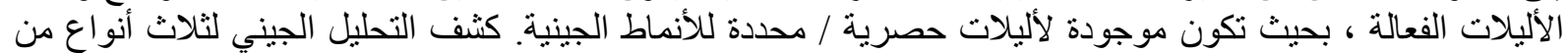
Artemisia monosperma

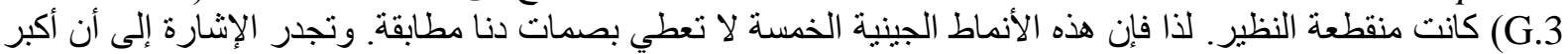

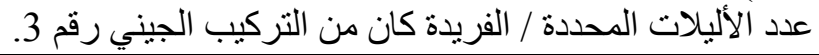

المجلة العلمية لكلية الزراعة - جامعة القاهرة المجلد (71) العدد الرابع (أكتوبر 2020):331-340. 